\title{
An Orally Administered Redox Nanoparticle that Accumlates in the Colonic Mucosa and Reduces Colitis in Mice
}

Long Binh Vong*, Tsutomu Tomita ${ }^{*} \ddagger$, Toru Yoshitomi ${ }^{*}$, Hirofumi Matsui ${ }^{\S, \|}$ and Yukio Nagasaki ${ }^{*}, \S, \uparrow$

*Department of Materials Science, Graduate School of Pure and Applied Sciences, University of Tsukuba, Tsukuba, Japan; ${ }^{\ddagger}$ Timelapse Vision Inc., Asaka, Saitama, Japan;

${ }^{\S}$ Master’s School of Medical Sciences, Graduate School of Comprehensive Human Sciences, University of Tsukuba, Tsukuba, Japan; "Division of Gastroenterology, Graduate School of Comprehensive Human Sciences, University of Tsukuba, Tsukuba, Japan; and "Satellite Laboratory, International Center for Materials Nanoarchitectonics (WPI-MANA), National Institute for Materials Science (NIMS), University of Tsukuba, Tsukuba, Japan

\section{Grant Support}

A part of this work was supported by Grant-in-Aid for Scientific Research A (21240050) and Grant-in-Aid for Research Activity Start-up (22800004) and the World Premier International Research Center Initiative (WPI Initiative) on Materials Nanoarchitronics of the Ministry of Education, Culture, Sports, Science and Technology (MEXT) of Japan. 


\section{Correspondence}

Prof. Yukio Nagasaki, Department of Materials Science, Graduate School of Pure and Applied Sciences, Master's School of Medical Sciences, Graduate School of Comprehensive Human Sciences, Satellite Laboratory, International Center for Materials Nanoarchitectonics (WPI-MANA), National Institute for Materials Science (NIMS), University of Tsukuba, Tennoudai 1-1-1, Tsukuba, Ibaraki, 305-8573, Japan E-mail address: yukio@nagalabo.jp

Phone: +81-29-853-5749

Fax: +81-29-853-5749

\section{Conflicts of interest}

The authors declare that they have no competing financial interests.

\section{Author contributions}

Y.N. designed the experiments and wrote the manuscript. L.B.V. and T.Y. designed and carried out the experiments, analyzed the results and wrote the manuscript. T.T. carried out the experiments of in vivo live imaging. H.M. designed colitis model in mice. 
BACKGROUND AND AIMS: Drugs used to treat patients with ulcerative colitis (UC) are not always effective because of non-specific distribution, metabolism in gastrointestinal tract, and side effects. We designed a nitroxide radical-containing nanoparticle $\left(\mathrm{RNP}^{\mathrm{O}}\right)$ that accumulates specifically in the colon to suppress inflammation and reduce the undesirable side effects of nitroxide radicals.

METHODS: $\mathrm{RNP}^{\mathrm{O}}$ was synthesized by assembly of an amphiphilic block copolymer that contains stable nitroxide radicals in an ether-linked hydrophobic side chain. Biodistribution of $\mathrm{RNP}^{\mathrm{O}}$ in mice was determined from radioisotope and electron spin resonance measurements. The effects of $\mathrm{RNP}^{\mathrm{O}}$ were determined in mice with dextran sodium sulfate (DSS)-induced colitis and compared with those of low-molecular-weight drugs (4-hydroxyl-2,2,6,6-tetramethylpiperidine-1-oxyl [TEMPOL] or mesalamine).

RESULTS: $\mathrm{RNP}^{\mathrm{O}}$, with a diameter of $40 \mathrm{~nm}$ and a shell of poly(ethylene glycol), had a significantly greater level of accumulation in the colonic mucosa than low-molecular-weight TEMPOL or polystyrene latex particles. $\mathrm{RNP}^{\mathrm{O}}$ was not absorbed into the bloodstream through the intestinal wall, despite its long-term retention in the colon, which prevented its distribution to other parts of the body. Mice with DSS-induced colitis had significantly lower disease activity index and less inflammation following 7 days of oral administration of $\mathrm{RNP}^{\mathrm{O}}$, compared with 
DSS-induced colitis mice or mice given low-molecular-weight TEMPOL or mesalamine.

CONCLUSION: We designed an orally administered $\mathrm{RNP}^{\mathrm{O}}$ that accumulates specifically in the colons of mice with colitis and is more effective in reducing inflammation than low-molecular-weight TEMPOL or mesalamine. $\mathrm{RNP}^{\mathrm{O}}$ might be developed for treatment of patients with UC.

Key words: Nitroxide Radical-containing Nanoparticles; Inflammatory Bowel Disease; Reactive Oxygen Species; Nanotherapy.

Abbreviation used in this paper: AUC, area under the concentration-time curve; CD, Crohn's disease; CMS, chloromethylstyrene; DAI, disease activity index; DHE dihydroethidium; DSS, dextran sodium sulfate; ESR, electron spin resonance; IBD, inflammatory bowel disease; IL, interleukin; H\&E, hematoxylin and eosin; GIT, gastrointestinal tract; $\quad$ MeO-PEG- $b$-PCMS, methoxy-poly(ethylene glycol)- $b$-poly(chloromethylstyrene); $\quad$ MeO-PEG- $b$-PMOT, methoxy-poly(ethylene glycol)-b-poly[p-4-(2,2,6,6-tetramethylpiperidine-1-oxyl)oxymethylstyrene];

MeO-PEG-SH, methoxy-poly(ethylene glycol)-sulfanyl; MPO, myeloperoxidase; PEG, poly(ethylene glycol); $\quad$ PEG- $b$-PMNT, poly(ethylene 
glycol)-b-poly[p-4-(2,2,6,6-tetramethylpiperidine-1-oxyl)aminomethylstyrene]; RNP ${ }^{\mathrm{N}}$, nitroxide radical-containing nanoparticles prepared by PEG-b-PMNT; $\mathrm{RNP}^{\mathrm{O}}$, nitroxide radical-containing nanoparticles prepared by MeO-PEG-b-PMOT; TEMPOL, 4-hydroxyl-2,2,6,6-tetramethylpiperidine-1-oxyl; UC, ulcerative colitis. 
Inflammatory bowel disease (IBD), including Crohn's disease (CD) and ulcerative colitis (UC), affects millions of patients worldwide. ${ }^{1-4}$ Since the etiology and pathogenesis of IBD are not well understood, it is considered an intractable disease. The intestinal mucosa of patients with IBD is characterized by reactive oxygen species (ROS) overproduction and an imbalance of important antioxidants, leading to oxidative damage. Self-sustaining cycles of oxidant production may amplify inflammation and mucosal injury. ${ }^{5-8}$ In several experimental models, antioxidant compounds and free radical scavengers have improved colitis. ${ }^{9-11}$ However, these compounds are not completely effective due to a non-specific drug distribution, a low retention in the colon and side effects. If antioxidant compounds are specifically targeted to the diseased sites and effectively scavenge excessive generated ROS, they represent a safe and effective treatment for IBD.

Nanoparticles such as liposome and polymeric micelles have gained worldwide attention as a new medical technology, because they change biodistribution of drugs to result in therapeutic effect of drugs significantly. ${ }^{12,13}$ In particular, the intratumoral microdistribution of nanoparticle has been studied for over two decades that nanoparticles can accumulate in sites of tumor due to the increased vascular permeability. ${ }^{14-17}$ Recently, we have developed an amphiphilic block copolymer, 
poly(ethylene

glycol)-b-poly[p-4-(2,2,6,6-tetramethylpiperidine-1-oxyl)aminomethylstyrene]

(PEG-b-PMNT), possessing stable nitroxide radicals in the hydrophobic segment as a side chain via an amine linkage, which forms core-shell-type micelles in the physiological environment with an average diameter of about $40 \mathrm{~nm}$, and termed nitroxide radical-containing nanoparticle $\left(\mathrm{RNP}^{\mathrm{N}}\right) .{ }^{18}$ Nitroxide radicals are confined in the core of this micelle, which shows high biocompatibility, including long-term blood circulation when administered intravenously and low toxicity. Therefore, $\mathrm{RNP}^{\mathrm{N}}$ has been studied for therapy in oxidative stress injuries ${ }^{18-22}$ and bioimaging. ${ }^{23,24}$ For example, $\mathrm{pH}$-sensitive $\mathrm{RNP}^{\mathrm{N}}$ works effectively in acute renal injury ${ }^{18}$ and cerebral ischemia-reperfusion ${ }^{19}$ because it disintegrates in acidic conditions of diseased area by protonation of amino groups. However, $\mathrm{pH}$-disintegrative character is not suitable for the treatment of UC via oral administration.

In this study, we describe a novel nanotherapy for the treatment of UC via oral administration. In order to target the nanoparticle to the colon area, its accumulation in the colonic mucosa is optimized, preventing its uptake into the bloodstream. We designed a new redox polymer, methoxy-poly(ethylene glycol)-b-poly[p-4-(2,2,6,6-tetramethylpiperidine-1-oxyl)oxymethylstyrene] 
(MeO-PEG-b-PMOT), which is an amphiphilic block copolymer with stable nitroxide radicals in a hydrophobic segment as a side chain via an ether linkage and forms 40-nm-diameter core-shell-type micelles $\left(\mathrm{RNP}^{\mathrm{O}}\right)$ by self-assembly in the aqueous environments regardless of $\mathrm{pH}$ (Figure $1 A$ ). Here, we investigate specific accumulation of $\mathrm{RNP}^{\mathrm{O}}$ in colon after oral administration by comparison to low-molecular-weight compound, 4-hydroxyl-2,2,6,6-tetramethylpiperidine-1-oxyl (TEMPOL) and commercial available polystyrene latex particles with different sizes from $40 \mathrm{~nm}$ to 1 $\mu \mathrm{m}$. Also, we examine the therapeutic effect of $\mathrm{RNP}^{\mathrm{O}}$ on dextran sodium sulfate (DSS)-induced colitis model in mice, compared to low-molecular-weight TEMPOL and mesalamine, a commercial anti-ulcer drug. Our results show that $\mathrm{RNP}^{\mathrm{O}}$ significantly accumulates in colonic mucosa area, especially inflammatory sites, without absorption into bloodstream and has an extremely high therapeutic efficiency in mice with DSS-induced colitis (Figure 1B).

\section{Materials and Methods}

\section{Preparation of $\operatorname{RNP}^{O}$}

$\mathrm{RNP}^{\mathrm{O}}$ was prepared by a self-assembling MeO-PEG-b-PMOT block

copolymer, as previously reported. $^{18}$ Briefly, methoxy-poly(ethylene 
glycol)-b-poly(chloromethylstyrene) (MeO-PEG-b-PCMS) was synthesized by the radical telomerization of chloromethylstyrene (CMS) using methoxy-poly(ethylene glycol)-sulphanyl (MeO-PEG-SH; $\mathrm{Mn}=5,000$ ) as a telogen. The chloromethyl groups were converted to TEMPOs via a Williamson ether synthesis of benzyl chloride in the MeO-PEG- $b$-PCMS block copolymer with the alkoxide of TEMPOL, as previously reported. $\mathrm{RNP}^{\mathrm{O}}$ was prepared from MeO-PEG-b-PMOT by dialysis method; Micelle without nitroxide radicals was similarly prepared from MeO-PEG- $b$-PCMS as a control and termed "micelle".

Preparation of rhodamine-labeled $R N P^{O},{ }^{125} I$-labeled $R N P^{O}$, polystyrene latex particles with nitroxide radicals

Detailed methods were described in Supplementary Materials and Methods section.

\section{Animals}

All experiments were carried out using 7-week-old male ICR mice (32-35 g) purchased from Charles River Japan, Inc. Mice were maintained in the experimental animal facilities at the University of Tsukuba. All experiments were performed according to the Guide for the Care and Use of Laboratory Animals at the University of 
Tsukuba.

\section{Localization of $\operatorname{RNP}^{O}$ in the colon}

Localization of $\mathrm{RNP}^{\mathrm{O}}$ in the colon was determined by fluorescent rhodamine-labeled $\mathrm{RNP}^{\mathrm{O}}$. Rhodamine-labeled $\mathrm{RNP}^{\mathrm{O}}$ was prepared via thiourethane bond between MeO-PEG- $b$-PMOT possessing reduced TEMPO moieties and rhodamine B isothiocyanatein (see Supplementary Materials and Methods). Mice were killed 4 hours after oral administration of $1 \mathrm{~mL}$ of rhodamine-labeled $\mathrm{RNP}^{\mathrm{O}}(5 \mathrm{mg} / \mathrm{mL})$. Residues in the colon were gently removed with phosphate buffered saline (50 mM, pH 7.4), and 7- $\mu \mathrm{m}$ thick colon sections were prepared. Localization of rhodamine-labeled $\mathrm{RNP}^{\mathrm{O}}$ was recorded using a fluorescent microscope.

\section{Accumulation of $R_{N P}^{O}$ in the colon}

Accumulation of $\mathrm{RNP}^{\mathrm{O}}$ was determined by ESR assay. One $\mathrm{mL}$ of low-molecular-weight TEMPOL, $\mathrm{RNP}^{\mathrm{O}}$ and different sized polystyrene latex particles with an equivalent nitroxide concentration $(1.33 \mathrm{mg} ; 7.5 \mu \mathrm{M})$ were orally administered to mice. Mice were killed 1, 4, 12, 24, and 48 hours after oral administration. Whole colons were homogenized in $1 \mathrm{~mL}$ of phosphate buffered saline (50 mM, pH 7.4) 
containing potassium ferricyanide $(50 \mathrm{mM})$. The ESR signal intensities in homogenized samples were measured by an X-band ESR spectrometer (JES-TE25X, JEOL, Tokyo, Japan) at room temperature. The amount of nitroxide radicals in the colon was determined by ESR measurements under the following conditions: frequency, 9.41 GHz; power, $10.00 \mathrm{~mW}$; center field, 333.3; sweep width, $5 \mathrm{mT}$; sweep time, $0.5 \mathrm{~min}$; modulation, $0.1 \mathrm{mT}$; time constant, $0.1 \mathrm{~s}$.

\section{Biodistribution of $R_{N P}^{O}$}

${ }^{125}$ I-labebled $\mathrm{RNP}^{\mathrm{O}}$ was prepared via reaction between $\mathrm{RNP}^{\mathrm{O}}$ and $\mathrm{Na}\left[{ }^{125} \mathrm{I}\right]$ with present of chloramine-T as a catalyst (see Supplementary Materials and Methods). Mice were fasted for 1 day before the experiment and $0.5 \mathrm{~mL}$ of ${ }^{125} \mathrm{I}$-labeled $\mathrm{RNP}^{\mathrm{O}}$ (20 $\mathrm{mg} / \mathrm{mL}$ ) was orally administered. Then, mice were sacrificed at $0.25,0.5,1,2,4,8,12$, and 24 hours after oral administration. The major digestive organs (small intestine, cecum, and colon) and blood were isolated, and their radioactivities were measured by a $\gamma$-counter (ARC-380, Aloka, Japan). The percentage of radioactivity in each organ was determined based on the initial total radioactivity.

\section{Induction of colitis by DSS and drug administration}


Colitis in mice was induced by 3\% (wt/vol) DSS (5,000 daltons; Wako Pure Chemicals) supplemented in the drinking water for 7 days. The experiment was designed to six groups: normal control group, DSS-injured group, low-molecular-weight TEMPOL-treated group, micelle-treated group, $\mathrm{RNP}^{\mathrm{O}}$-treated group and mesalamine-treated group. The equivalent doses of drugs $(0.2 \mathrm{mM} / \mathrm{kg})$ were orally administered daily during the 7 days of DSS treatment. The concentrations of low-molecular-weight TEMPOL, micelle and $\mathrm{RNP}^{\mathrm{O}}$ were adjusted in distilled water, and the solutions were filtered with a $0.25-\mu \mathrm{m}$ cellulose acetate filter. Mesalamine was suspended in $0.5 \%$ (wt/vol) carboxymethyl cellulose.

Evaluation of colitis severity by disease activity index (DAI) and colon length; Histological assessment; Measurements of myeloperoxidase (MPO) activity, interleukin (IL)-1 $\beta$ and superoxide production

Detailed methods were described in Supplementary Materials and Methods section.

Intravital observation by in vivo live imaging

Aqueous solution of DSS (3\% wt/vol) was administered by free access for 7 days to induce colitis in mice. One $\mathrm{mL}$ of $\mathrm{RNP}^{\mathrm{O}}(10 \mathrm{mg} / \mathrm{mL})$ was orally administered 
daily. After 7 days of treatment, mice were anesthetized with urethane $(15 \mathrm{~g} / \mathrm{kg}$, Sigma-Aldrich) and an arc-shaped incision was made in the peritoneum to expose the colon. Then, approximately $1 \mathrm{~cm}$ length incision was made to observe the colonic mucosa and the remained contents in the colon were removed gently by physiological saline. Mice were set on the stage of microscope and in vivo live imaging was acquired after 2 hours with a microscope. Dead cells in colonic mucosa were identified by staining of propidium iodide in physiological buffer (50 $\mu \mathrm{g} / \mathrm{mL}$; Wako Pure Chemicals) under an excitation wavelength of $488 \mathrm{~nm}$ and an emission wavelength of $515 \mathrm{~nm}$.

\section{Survival rate experiment}

The survival rate of mice was determined by replacing drinking water with a 3\% (wt/vol) solution of DSS for 15 days. Starting on day 5, drugs were oral administered daily until day 15 , and the number of surviving mice was counted until day 15.

\section{Statistical analysis}

All values are expressed as mean \pm standard error of mean (SEM). Differences between groups were examined for statistical significance using the one-way and 
two-way ANOVA, followed by Bonferroni post-hoc test (SPSS ${ }^{\circledR}$ software, IBM Corp., NY, USA). A $P$-value $<.05$ was considered significant for all statistical analyses.

\section{Results}

\section{Specific accumulation of $R N P^{O}$ in colonic mucosa and inflamed colon area}

The accumulation of nanoparticles in the colon area is one of the most important features for an effective nanomedicine against UC. Firstly, we orally administered fluorescently labeled nanoparticles, and analyzed the accumulation of these nanoparticles in the colon by fluorescent microscopy. Here, we prepared rhodamine-labeled $\mathrm{RNP}^{\mathrm{O}}$ (see Supplementary Materials and Methods). After oral administration of rhodamine-labeled $\mathrm{RNP}^{\mathrm{O}}$, there was a strong fluorescent signal at the colonic mucosa area, as compared to oral administration of low-molecular-weight fluorescein (Figure 2A). This result indicates effective accumulation of $\mathrm{RNP}^{\mathrm{O}}$ in the colonic mucosa.

In order to quantify the accumulation of nanoparticles in the colon area, we compared $\mathrm{RNP}^{\mathrm{O}}$ with different sizes of commercial available polystyrene latex particles and low-molecular-weight compound, TEMPOL. Because we introduced nitroxide radicals into the particles, their accumulation could be quantitatively monitored by 
electron spin resonance (ESR) measurements. When we orally administered low-molecular-weight TEMPOL to mice, almost no ESR signal was observed in the colon, as shown in Figure $2 B$. In contrast, polystyrene latex particles showed a higher accumulation in the colon compared to low-molecular-weight TEMPOL. From these results, the size-dependent accumulation in colon was observed. Polystyrene latex particles with $40 \mathrm{~nm}$ and $100 \mathrm{~nm}$ in size accumulated higher than large-sized particles $(0.5 \mu \mathrm{m}$ and $1 \mu \mathrm{m})$, which is consistent with previous reports. ${ }^{25,26}$ Interestingly, when $^{2}$ $\mathrm{RNP}^{\mathrm{O}}$ was administrated orally to mice, considerable high accumulation of $\mathrm{RNP}^{\mathrm{O}}$ in colon was observed, as compared to polystyrene latex particles, even though the same size $(40 \mathrm{~nm})$. The area under the concentration-time curve (AUC), an important parameter in biopharmaceuticals and pharmacokinetics, of $\mathrm{RNP}^{\mathrm{O}}$ was 1223.3 , which was significantly higher than 27.8 of low-molecular-weight TEMPOL. The AUC of polystyrene latex particles with sizes $40 \mathrm{~nm}, 100 \mathrm{~nm}, 0.5 \mu \mathrm{m}$ and $1 \mu \mathrm{m}$ were 249.5, 204.7, 83.7 and 32.9, respectively. High colloidal stability of $\mathrm{RNP}^{\mathrm{O}}$ due to the PEG tethered chains on the surface might be effective to accumulate in colonic mucosa as compared to polystyrene latex particles. The extremely high accumulation of $\mathrm{RNP}^{\mathrm{O}}$ in colonic mucosa can be anticipated for high performance efficiency as a colitis therapy. Next, we investigated the specific accumulation of $\mathrm{RNP}^{\mathrm{O}}$ in the injured colon. 
Aqueous solution of DSS (3\% wt/vol) was administered by free access to induce colitis in mice. We orally administered $\mathrm{RNP}^{\mathrm{O}}$ at day 5 and quantified the amount of $\mathrm{RNP}^{\mathrm{O}}$ in the colon by ESR measurements 4 hours after administration. Interestingly, the amount of accumulated $\mathrm{RNP}^{\mathrm{O}}$ in the colon of DSS-injured mice was $50 \%$ higher than that in the normal colon under the same administration conditions $(1.57 \pm 0.18 \mu \mathrm{g} / \mathrm{cm}$ of colon length for DSS-treated mice and $1.01 \pm 0.13 \mu \mathrm{g} / \mathrm{cm}$ of colon length for normal mice) (Figure 2C). This result suggested that $\mathrm{RNP}^{\mathrm{O}}$ accumulates to a greater extent in inflammatory sites, such as in UC.

\section{Distribution and non-absorption into bloodstream of $\operatorname{RNP}^{O}$ after oral administration}

As previously mentioned, we confirmed the specific accumulation of $\mathrm{RNP}^{\mathrm{O}}$ in the DSS-injured colon. It is also important to estimate the non-specific distribution in whole body. Therefore, to precisely evaluate non-specific distribution, we used radioisotope ${ }^{125}$ I-labeled $\mathrm{RNP}^{\mathrm{O}}$ (see Supplementary Materials and Methods), which moved from the small intestine, to the cecum, and to the colon over time after oral administration (Figure 3A). Specifically, in the first hour after administration, 3.2\% of the initial dose of $\mathrm{RNP}^{\mathrm{O}}$ had reached the colon. It accumulated to a maximum of $14.5 \%$ of the initial dose 4 hours after administration. Twenty-four hours after administration, 
there was $0.5 \%$ of the initial dose of $\mathrm{RNP}^{\mathrm{O}}$ remaining in the colon. Importantly, we did not observe the uptake of $\mathrm{RNP}^{\mathrm{O}}$ into the bloodstream (Figure 3A). This is in sharp contrast to low-molecular-weight compounds, such as TEMPOL. This difference in bloodstream uptake via the gastrointestinal tract (GIT) was further confirmed by ESR measurements. Low-molecular-weight TEMPOL was absorbed into the bloodstream through the GIT in normal mice and even more in DSS-treated mice (Figure 3B). However, when $\mathrm{RNP}^{\mathrm{O}}$ was administered orally, there was no observable ESR signal in the blood, which was consistent with the results from the experiments of ${ }^{125}$ I-labeled $\mathrm{RNP}^{\mathrm{O}}$. In the present study, oral nanotherapy with $\mathrm{RNP}^{\mathrm{O}}$ prevented uptake into the bloodstream, suggesting a lack of systemic side effects.

\section{Stability of $R N P^{O}$ in GIT}

Next, we evaluated the stability of orally administered $\mathrm{RNP}^{\mathrm{O}}$ in the GIT using ESR spectra of $\mathrm{RNP}^{\mathrm{O}}$ in the colon. The ESR signals of low-molecular-weight TEMPOL in the colon showed a sharp triplet due to an interaction between the ${ }^{14} \mathrm{~N}$ nuclei and the unpaired electron, as previously reported ${ }^{18}$ (Figure 3B, inset, grey spectrum). In contrast, the ESR signals of $\mathrm{RNP}^{\mathrm{O}}$ in the colon were broad (Figure 3B, inset, black spectrum), suggesting that $\mathrm{RNP}^{\mathrm{O}}$ remains as core-shell type micelle even in the GIT. The stability 
of self-assembled $\mathrm{RNP}^{\mathrm{O}}$ with several tens of nanometers in GIT could prevent the uptake into the bloodstream through the intestinal wall. After reaching colon, $\mathrm{RNP}^{\mathrm{O}}$ is accumulated in inflamed and mucosal area, followed by effectively scavenging ROS. It is noted that $\mathrm{RNP}^{\mathrm{N}}$, which contains amino group as side chains in the hydrophobic segment, is absorbed into the bloodstream when administered orally (data not shown). It is likely that the disintegration of $\mathrm{RNP}^{\mathrm{N}}$ in the stomach facilitates its uptake into the bloodstream through the intestinal wall, which was not observed in $\mathrm{RNP}^{\mathrm{O}}$.

\section{Therapeutic effect of $\mathrm{RNP}^{O}$ on DSS-induced colitis in mice}

Since orally administered $\mathrm{RNP}^{\mathrm{O}}$ accumulated in the colonic mucosa of DSS-injured mice and was not absorbed into the bloodstream, it is anticipated to be an ideal nanomedicine for UC treatment. Therefore, we investigated its therapeutic and suppressive effects on DSS-induced colitis model in mice. $\mathrm{RNP}^{\mathrm{O}}$ was orally administered daily to DSS-injured mice for 7 days. Additional DSS-injured mice were treated with low-molecular-weight TEMPOL, commercially anti-ulcer mesalamine and micelle without nitroxide radicals as controls. After 7 days of treatment, we assessed the severity of colitis on the basis of $\mathrm{DAI}^{27}$ (see Supplementary Table 1), colon length, and histological analysis. Mice treated with DSS had a significant increase in DAI and 
shortening of the colon compared to control mice (Figure $4 A, B$ ). The treatments with low-molecular-weight TEMPOL or mesalamine showed efficiency to decrease DAI as compared to DSS-treated mice, though this efficiency was not significant. On the contrary, $\mathrm{RNP}^{\mathrm{O}}$-treated mice showed much lower DAI and preserved colon length compared to DSS-treated mice $(P<.01)$ and other low-molecular-weight drugs-treated mice. It should be noted that no effect was observed when polymeric micelle without nitroxide radicals was administered instead of $\mathrm{RNP}^{\mathrm{O}}$. Additionally, histological analyses showed that mucosal structures of DSS- and micelle-treated mice were significantly damaged, viz., destruction of crypts and high levels of neutrophil invasion were observed in these mice. Low-molecular-weight TEMPOL- or mesalamine-treated mice showed moderately damaged mucosal structures. Contrary of those treatments, $\mathrm{RNP}^{\mathrm{O}}$-treated mice showed almost similar to that of control mice (Figure $4 C$ ), indicating the significant therapeutic effect of $\mathrm{RNP}^{\mathrm{O}}$ on DSS-induced colitis in mice.

We then analyzed ability of $\mathrm{RNP}^{\mathrm{O}}$ to suppress systemic inflammation in DSS-induced colitis. Hematological analyses were performed to reveal the massive infiltration of leukocytes. Blood from $\mathrm{RNP}^{\mathrm{O}}$-treated mice had a significant lower level of white blood cells compared to DSS- and micelle-treated mice $(P<.05)$, indicating lower levels of neutrophil invasion in $\mathrm{RNP}^{\mathrm{O}}$-treated mice (Figure $5 A$ ). 
Low-molecular-weight TEMPOL and mesalamine showed the effect to suppress white blood cells in DSS-treated mice; however, the significance was not observed. Furthermore, results of the hematological analysis indicated higher levels of red blood cells and hemoglobin in the blood of $\mathrm{RNP}^{\mathrm{O}}$-treated mice (Figure 5B,C). This suggests that the intestinal wall was protected from hemorrhage in $\mathrm{RNP}^{\mathrm{O}}$-treated mice. We further investigated the desquamation of impaired epithelial cells and cell death in colonic mucosa by intravital observation using in vivo microscopic live imaging and propidium iodide staining. ${ }^{28}$ The results showed that a great number of desquamated cells and cell death existed in colonic mucosa of DSS-treated mice (Figure 5D, Supplementary Video 1). In contrast, in colonic mucosa of $\mathrm{RNP}^{\mathrm{O}}$-treated mice, the desquamation and cell death was remarkably suppressed. On the basis of these results, it was confirmed that the colonic injury is protected by the oral administration of $\mathrm{RNP}^{\mathrm{O}}$.

\section{$\mathrm{RNP}^{O}$ suppresses pro-inflammatory mediators and enhances survival rate in mice}

In addition, after 7 days of treatment, we determined pro-inflammatory mediators in the colonic mucosa, including MPO activity, IL-1 $\beta$ and superoxide. These pro-inflammatory mediators are well-known markers of inflammation and play an important role in UC. Low-molecular-weight TEMPOL and mesalamine did not effectively suppress these pro-inflammatory mediators induced by DSS (Figure $6 A-C$ ). 
On the other hand, $\mathrm{RNP}^{\mathrm{O}}$-treated mice showed a significant suppression of pro-inflammatory mediators in colonic tissue $(P<.01)$. It should be noted that no therapeutic effect was observed for polymeric micelle without nitroxide groups, indicating that effective delivery of nitroxide groups in colonic mucosa area is one of the most important factors for UC treatment. Because low-molecular-weight drugs tend to be absorbed into the bloodstream via mesentery, sufficient dose of drugs might not reach to target area to result in low therapeutic efficacy. Side effects in whole body should also be considered such kind of low-molecular weight drugs. Finally, we investigated the effect of orally administered $\mathrm{RNP}^{\mathrm{O}}$ on the survival rate of mice with colitis induced by 5-day administration of DSS. After 15 days of treatment, orally administered low-molecular-weight TEMPOL and mesalamine slightly increased the survival rate (33.3\% and 50\%, respectively) compared with DSS- and micelle-treated mice (16.7\%) (Figure 6D). On the other hand, $\mathrm{RNP}^{\mathrm{O}}$ treatment significantly increased the survival rate of DSS-treated mice to $83.3 \%$. This indicates that $\mathrm{RNP}^{\mathrm{O}}$ has not only suppressive but also therapeutic effects on mice with DSS-induced colitis.

\section{Discussion}


Despite significant advances in treatments, IBD remains a major clinical problem, because no drug is entirely effective. For many years, there were only 2 treatment options for IBD: corticosteroids and mesalamine. ${ }^{29,30}$ Although they are effective in treating IBD in some extent, their severe side effects have raised significant concerns among both physicians and patients, and limited their use. In addition, anti-TNF- $\alpha$ antibody is employed to suppress inflammation of UC, which works well though it is cost-oriented therapy with multiple side effects. ${ }^{31}$ Recently, many promising low-molecular-weight medications, such as antioxidants, have been found beneficial in experimental models of UC. ${ }^{9-11,32}$ Unfortunately, results of clinical trials investigating these promising drugs have been largely negative. The drawbacks of current low-molecular-weight drugs are poor stability in stomach, low solubility and side effects on whole body when they enter the bloodstream. In this study, we have developed a novel nitroxide radical-containing nanoparticle $\mathrm{RNP}^{\mathrm{O}}$ that accumulates specifically in colon area to suppress the inflammation in DSS-induced colitis mice. For UC treatment via oral administration, this nanoparticle showed excellent properties, including high accumulation in inflamed tissues of colon and non-absorption into the bloodstream. 
Here, we found that the accumulation in colon area depends on the sizes and PEGylated character of particles. Both low-molecular-weight drugs, submicron- and micron-sized polystyrene latex particles showed poor accumulation in colon, whereas higher accumulation of particles with approximately several tens of nanometers was observed. Optimal size of several tens of nanometers allowed easier diffusion in the mucosa compared to larger sized particles..$^{25,26,33}$ In addition, 40-nm-diameter $\mathrm{RNP}^{\mathrm{O}}$ with PEG shell showed significantly high accumulation and long retention in colon area compared to polystyrene latex particles with similar size of $40 \mathrm{~nm}$. PEGylated character of $\mathrm{RNP}^{\mathrm{O}}$ might protect nitroxide radicals in the hydrophobic core from hash conditions of GIT after oral administration, resulting in the significant accumulation in colon area. ${ }^{34}$ Furthermore, PEG chains of $\mathrm{RNP}^{\mathrm{O}}$ may achieve mucoadhesion due to their ability to inter-diffuse among the mucus network and polymer entanglement with mucin, which is composed of glycoprotein. ${ }^{35}$ Therefore, PEGylated character of RNP ${ }^{\mathrm{O}}$ showed much significant effect on its accumulation in colonic mucosa. Eventually, we observed the accumulation of $\mathrm{RNP}^{\mathrm{O}}$ in colon is almost 50 times higher than that of low-molecular-weight TEMPOL. To deliver sufficient dose of anti-inflammatory drugs for UC treatment, high dose of drugs is required, however it leads to undesirable side effects, because almost all low-molecular-weight drugs tend to metabolize in upper GIT 
or absorb into bloodstream. ${ }^{36,37}$ In case of $\mathrm{RNP}^{\mathrm{O}}$, no absorption into bloodstream was observed via oral administration route, which improves accumulation in colon region and prevents side effects to whole body. Another interesting phenomenon in our study is the higher accumulation of nanoparticles in inflammatory colon than healthy colon. Mucus layer in colon area is significantly thicker than that in small intestine, which is considered as a significant barrier to nanoparticle penetration. ${ }^{38}$ In colon of patients with UC, the overall thickness of the adherent mucus layer is reduced due to the reduction of goblet cells, ${ }^{38,39}$ resulting in the facile penetration of nanoparticles in inflammatory tissues. In addition, the opening tight junction of epithelium cells in UC is another explanation for higher accumulation of nanoparticles. ${ }^{40}$ It should be noted that no absorption of $\mathrm{RNP}^{\mathrm{O}}$ into bloodstream was observed even in colitis mice.

After investigating the distribution of $\mathrm{RNP}^{\mathrm{O}}$ in GIT, we used DSS-induced colitis model mice to compare suppressive effect of $\mathrm{RNP}^{\mathrm{O}}$ with low-molecular-weight TEMPOL and mesalamine, a commercial medication for UC treatment. Our results showed that low-molecular-weight TEMPOL and mesalamine did not clearly show their effects, whereas $\mathrm{RNP}^{\mathrm{O}}$ effectively reduced the severity of colitis by suppression of DAI and damage of colonic architecture. It is noted that micelle without nitroxide radicals did not show any therapeutic effect at all on colitis mice, indicating that ROS 
scavenging character of nitroxide radicals plays critical role in the effect of $\mathrm{RNP}^{\mathrm{O}}$ on colitis mice. Further investigations, it is confirmed that $\mathrm{RNP}^{\mathrm{O}}$ did not simulate the whole body immune system as well as effectively suppressed pro-inflammatory mediators such as MPO, IL- $1 \beta$ and superoxide. The therapeutic efficiency of $\mathrm{RNP}^{\mathrm{O}}$ was further confirmed by survival data, which showed higher survival rate of $\mathrm{RNP}^{\mathrm{O}}$-treated mice compared to low-molecular-weight TEMPOL- or mesalamine-treated mice.

In conclusion, we have developed a novel nitroxide radical-containing nanoparticle, $\mathrm{RNP}^{\mathrm{O}}$, which possesses anti-oxidative nitroxide radicals in the core for treatment of DSS-induced colitis mice. $\mathrm{RNP}^{\mathrm{O}}$ significantly accumulated not only in the mucosa but also higher in inflammatory sites of the colon, resulting in a high therapeutic effect, which was not observed in low-molecular-weight drugs. In addition, $\mathrm{RNP}^{\mathrm{O}}$ may lack the undesirable side effects of low-molecular-weight TEMPOL, since it is not absorbed into the bloodstream. Our results indicated that the therapeutic efficiency of nitroxide radicals could be successfully enhanced by using nanoparticles to suppress inflammation in the colon area and reduce undesirable side effects. Therefore, we believe that $\mathrm{RNP}^{\mathrm{O}}$ may become an important therapeutic agent for the treatment of UC. 


\section{Acknowledgements}

One of the authors, L.B.V., would like to express his sincere appreciation for the research fellowship of The Japan-East Asia Network of Exchange for Students \& Youths (JENESYS) between University of Science Ho Chi Minh, Vietnam and University of Tsukuba, Japan.

\section{Figure Legends:}

Figure 1. Schematic illustration of $\mathrm{RNP}^{\mathrm{O}}$ and nanotherapy for DSS-induced colitis in mice. (A) $\mathrm{RNP}^{\mathrm{O}}$ is prepared by self-assembly of a poly(ethylene glycol)-b-poly(4-methylstyrene) block copolymer possessing nitroxide radical TEMPO moieties. (B) After oral administration, low-molecular-weight drugs, such as TEMPOL, are degraded and absorbed into the bloodstream in stomach and small intestine before reaching the colon. In contrast, $\mathrm{RNP}^{\mathrm{O}}$ is stable and withstands the harsh conditions of the gastrointestinal tract (GIT), and reach the colon to scavenge ROS, especially sites of inflammation.

Figure 2. Specific accumulation of $\mathrm{RNP}^{\mathrm{O}}$ in mice with colitis. $(A)$ Localization of $\mathrm{RNP}^{\mathrm{O}}$ in the colon was determined with rhodamine-labeled $\mathrm{RNP}^{\mathrm{O}}$. Mice were sacrificed 4 hours after oral administration of $1 \mathrm{~mL}$ of rhodamine-labeled $\mathrm{RNP}^{\mathrm{O}}$ at a dose of 5 
$\mathrm{mg} / \mathrm{mL}(n=3)$, and colon sections were prepared. Localization of rhodamine-labeled $\mathrm{RNP}^{\mathrm{O}}$ in the colon was analyzed by fluorescent microscopy. Scale bars, $200 \mu \mathrm{m}$. (B) Accumulation of low-molecular-weight TEMPOL, $\mathrm{RNP}^{\mathrm{O}}$ and polystyrene latex particles in the colon. After oral administration of low-molecular-weight TEMPOL, $\mathrm{RNP}^{\mathrm{O}}$ and polystyrene latex particles with equivalent nitroxide radicals (1.33 mg; 7.5 $\mu \mathrm{M})$, the amount of nitroxide radicals was measured by ESR. The data are expressed as mean \pm SEM, $n=3$. (C) Specific accumulation of $\mathrm{RNP}^{\mathrm{O}}$ in the inflamed colon. Colitis was induced in mice by supplementing the drinking water with DSS (3\% wt/vol) for 5 days. The amount of nitroxide radicals in the normal colon and the inflamed colon was determined by ESR measurement 4 hours after administration of $\mathrm{RNP}^{\mathrm{O}}$. The data are expressed as mean \pm SEM, $n=3$.

Figure 3. Biodistribution of $\mathrm{RNP}^{\mathrm{O}}$ in GIT and bloodstream. (A) The biodistribution of $\mathrm{RNP}^{\mathrm{O}}$ was determined using ${ }^{125} \mathrm{I}$-labeled $\mathrm{RNP}^{\mathrm{O}}$. The percentages of radioactivity in each organ and in the blood were determined by comparison to the initial total radioactivity. The data are expressed as mean \pm SEM, $n=5$. (B) Absorption of low-molecular-weight TEMPOL and $\mathrm{RNP}^{\mathrm{O}}$ into the bloodstream of normal mice (solid line) and colitis mice (dashed line). After administration of low-molecular-weight 
TEMPOL and $\mathrm{RNP}^{\mathrm{O}}$, the amount of nitroxide radicals in the plasma was determined by ESR measurement. The data are expressed as mean $\pm \mathrm{SEM}, n=3$. (Inset) The ESR spectra of low-molecular-weight TEMPOL (grey spectrum) and $\mathrm{RNP}^{\mathrm{O}}$ (black spectrum) in the colon homogenate after $4 \mathrm{~h}$ oral administration.

Figure 4. Therapeutic effect of $\mathrm{RNP}^{\mathrm{O}}$ on DSS-induced colitis in mice. (A) Changes in disease activity index. Disease activity index is the summation of the stool consistency index (0-3), fecal bleeding index (0-3), and weight loss index (0-4). The data are expressed as mean $\pm \mathrm{SEM},{ }^{*} P<.05,{ }^{* *} P<.01$ and $* * * P<.001$ vs. control group; ${ }^{\ddagger} P$ $<.05$ and ${ }^{\boxplus} P<.001$ vs. DSS groups, $n=6-7$, two-way ANOVA, followed by Bonferroni post-hoc test. $(B)$ Preservation of colon length. After 7 days of treatment, the colon was collected and measured. The data are expressed as mean \pm SEM, $* * P<.01, n$ = 6-7. (C) Protection of mucosal architecture. After 7 days of treatment, the colon was collected, and 7- $\mu$ m-thick sections of distal colon were prepared. Sections of the distal colon were stained by hematoxylin and eosin (H\&E), and assessed histologically. Scale bars, $200 \mu \mathrm{m}$.

Figure 5. Hematological analyses in the peripheral blood and intravital observation of 
colon. (A-C) After 7 days of treatment, blood was collected by intracardiac puncture with a heparin-containing syringe, and hematological analyses were performed by automatic hematology analyzer (Celltac $\alpha$, MEK-6358; Nihon Kohden Co., Tokyo, Japan). Blood samples were analyzed for white blood cells (A), red blood cells (B), and hemoglobin $(C)$. The data are expressed as mean \pm SEM, $* P<.05, * * P<.01,{ }^{* * *} P$ $<.001, n=6$. (D) The desquamation of impaired epithelial cells and cell death in colonic mucosa were determined by in vivo microscopic live imaging and propidium iodide staining. The bright field images were acquired 2 hours after removing remains in the colon. The cell death images were recorded immediately after staining of propidium iodide under an excitation wavelength of $488 \mathrm{~nm}$ and an emission wavelength of $515 \mathrm{~nm}$.

Figure 6. $\mathrm{RNP}^{\mathrm{O}}$ reduced pro-inflammatory mediators and increased survival rate in colitis mice. $(A-C)$ After 7 days of treatment, colon homogenates were prepared, and MPO activity, superoxide, and IL-1 $\beta$ were measured. (A) MPO activity was determined by a colorimetric assay using o-dianisidine hydrochloride and $\mathrm{H}_{2} \mathrm{O}_{2}$ as substrates. (B) Measurement of IL- $1 \beta$ in colon homogenate was performed with an ELISA kit for mice. Protein content in the colon homogenate was determined by a BCA kit. (C) Generation 
of superoxide in colon homogenates was measured by dihydroethidium (DHE) fluorescence. The fluorescence intensity was measured with an excitation wavelength of $530 \mathrm{~nm}$ and an emission wavelength of $620 \mathrm{~nm}$. Superoxide values were expressed as intensity per mg of protein, and the superoxide value of the control group was standardized to $100 \%$. The data are expressed as mean $\pm \mathrm{SEM}, * P<.05$, ${ }^{* *} P<.01$, ${ }^{* * *} P<.001, n=6$. (D) The survival rate of mice was determined after 15 days of $3 \%$ (wt/vol) DSS treatment. Starting on day 5, test drugs were orally administered daily until day 15. The number of surviving mice was counted until day $15, n=6$.

\section{References}

1. Khor B, Gardet A, Xavier RJ. Genetics and pathogenesis of inflammatory bowel disease. Nat Rev 2011;474:307-317.

2. Podolsky DK. Inflammatory bowel disease. N Engl J Med 2002;347:417-429.

3. Abraham C, Cho HJ. Mechanism of disease inflammatory bowel disease. N Engl J Med 2009;361:2066-2078.

4. Edward VL. Clinical epidemiology offlimmmatory bowel disease: incidence, prevalence, and environmental influences. Gastroenterology 2004;126:1504-1517.

5. Simmonds NJ, Rampton DS. Inflammatory bowel disease a radical view. Gut 
1993;34:865-868.

6. Xavier RJ, Podolsky DK. Unravelling the pathogenesis of inflammatory bowel disease. Nat Rev 2007;448:427-434.

7. Babbs CF. Oxygen radicals in ulcerative colitis. Free Radic Biol Med 1992;13:169-182.

8. McCord JM. The evolution of free radicals and oxidative stress. Am J Med 2000;108:652-659.

9. Jin Y, Kotakadi VS, Ying L, et al. American ginseng suppresses inflammation and DNA damage associated with mouse colitis. Carcinogenesis 2008;29:2351-2359.

10. Ju J, Hao X, Lee MJ, et al. A $\gamma$-tocopherol-rich mixture of tocopherols inhibits colon inflammation and carcinogenesis in azoxymethane and dextran sulfate sodium-treated mice. Cancer Prev Re 2009;2:143-152.

11. Aggarwal BB, Harikumar KB. Potential therapeutic effects of curcumin, the anti-inflammatory agent, against neurodegenerative, cardiovascular, pulmonary, metabolic, autoimmune and neoplastic diseases. Int $\mathrm{J}$ Biochem Cell Biol 2009;41:40-59.

12. Kim B, Rutka J, Chan W. Nanomedicine. N Engl J Med 2010;36:2434-2443. 
13. Otsuka H, Nagasaki Y, Kataoka K. PEGylated nanoparticles for biological and pharmaceutical applications. Adv Drug Deliv Rev 2003;55:403-419.

14. Maeda H, Fang J, Inutsuka T, et al. Vascular permeability enhancement in solid tumor: various factors, mechanisms involved and its implications. Int Immunopharmacol 2003;3:319-328.

15. Weis SM, Cheresh DA. Tumor angiogenesis: molecular pathways and therapeutic targets. Nat Med 2011;17:1359-1370.

16. Davis ME, Chen ZG, Shin DM. Nanoparticle therapeutics: an emerging treatment modality for cancer. Nat rev Drug dis 2008;7:771-782.

17. Cabral H, Matsumoto Y, Mizuno K, et al. Accumulation of sub-100 nm polymeric micelles in poorly permeable tumours depends on size. Nat Nanotech 2011;6:815-823. 18. Yoshitomi T, Hirayama A, Nagasaki Y. The ROS scavenging and renal protective effects of $\mathrm{pH}$-responsive nitroxide radical-containing nanoparticles. Biomaterials 2011;32:8021-8028.

19. Marushima A, Suzuki K, Nagasaki Y, et al. Newly synthesized radical-containing nanoparticles enhance neuroprotection after cerebral ischemia-reperfusion injury. Neurosurgery 2011;68:1418-1426. 
20. Chonpathompikunlert P, Yoshitomi T, Han J, et al. Chemical nanotherapy: Nitroxyl radical-containing nanoparticle (RNP) protects neuroblastoma SH-SY5Y cells from a $\beta$-induced oxidative stress. Ther Deliv 2011;2:585-597.

21. Chonpathompikunlert P, Yoshitomi T, Han J, et al. The use of nitroxide radical-containing nanoparticles coupled with piperine to protect neuroblastoma SH-SY5Y cells from a $\beta$-induced oxidative stress. Biomaterials 2011;32:8605-8612.

22. Yoshitomi T, Nagasaki Y. Nitroxyl radical-containing nanoparticles for novel nanomedicine against oxidative stress injury. Nanomedicine 2011;6:509-518.

23 . Yoshitomi T, Suzuki R, Mamiya T, et al. pH-sensitive radical-containing-nanoparticle (RNP) for the L-band-EPR imaging of low $\mathrm{pH}$ circumstances. Bioconjugate Chem 2009;20:1792-1798.

24. Yoshitomi T, Miyamoto D, Nagasaki Y. Design of core-shell-type nanoparticles carrying stable radicals in the core. Biomacromolecules 2009;10:596-601.

25. Lamprecht A, Schafer U, Lehr CM. Size-dependent bioadhesion of micro- and nanoparticulate carriers to the inflamed colonic mucosa. Pharm Res 2001;18:788-793.

26. Francis MF, Cristea M, Winnik FM. Polymeric micelles for oral drug delivery: Why and how. Pure Appl Chem 2004;76:1321-1335. 
27. Cooper HS, Murthy SN, Shah RS, et al. Clinicopathologic study of dextran sulfate sodium experimental murine colitis. Lab Invest 1993;69:238-249.

28. Bryson GJ, Harmon BV, Collins RJ. A flow cytometric study of cell death: Failure of some models to correlate with morphological assessment. Immunol Cell Biol 1994;72:35-41.

29. Friend DR, Sellin J. Drug delivery in advancing the treatment of inflammatory bowel disease. Adv Drug Deliv Rev 2005;57:215-216.

30. Stephen BH. Medical therapy for ulcerative colitis 2004. Gastroenterology 2004;126:1582-1592.

31. Singh K, Chaturvedi R, Barry DP, et al. The apolipoprotein E-mimetic peptide COG112 inhibits NF-kappaB signaling, proinflammatory cytokine expression, and disease activity in murine models of colitis. J Biol Chem 2011;286:3839-3850.

32. Helieh S, Theresa S, Craig J, et al. Antioxidants as novel therapy in a murine model of colitis. J Nutr Biochem 2005;16:297-304.

33. Jiang W, Kim B, Rutka J, et al. Nanoparticle-mediated cellular response is size-dependent. Nat Nanotech 2008;3:145-150.

34. Tobio M, Sanchez A, Vila A, et al. The role of PEG on the stability in digestive 
fluids and in vivo fate of PEG-PLA nanoparticles following oral administration. Colloids Surf B 2000;18:315-323.

35. Lai SK, Wang YY, Hanes J. Mucus-penetrating nanoparticles for drug and gene delivery to mucosal tissues. Adv Drug Deliv Rev 2009;61:158-171.

36. Friend, D.R. New oral delivery systems for treatment of inflammatory bowel disease. Adv Drug Deliv Rev 2005;57:247-265.

37. Laroui H, Dalmasso G, Thu Nguyen HT, et al. Drug-loaded nanoparticles targeted to the colon with polysaccharide hydrogel reduce colitis in a mouse model. Gastroenterology 2010;138:843-853.

38. Ensign LM, Cone R, Hanes J. Oral drug delivery with polymeric nanoparticles: The gastrointestinal mucus barriers. Adv Drug Deliv Rev 2012;64:557-570.

39. Pullan RD, Thomas G, Rhodes M, et al. Thickness of adherent mucus gel on colonic mucosa in humans and its relevance to colitis. Gut 1994;35:353-359.

40. Cereijido M, Contreras RG, Flores-Benítez D, et al. New diseases derived or associated with the tight junction. Arch Med Res 2007;38:465-478. 


\section{Figure 1}

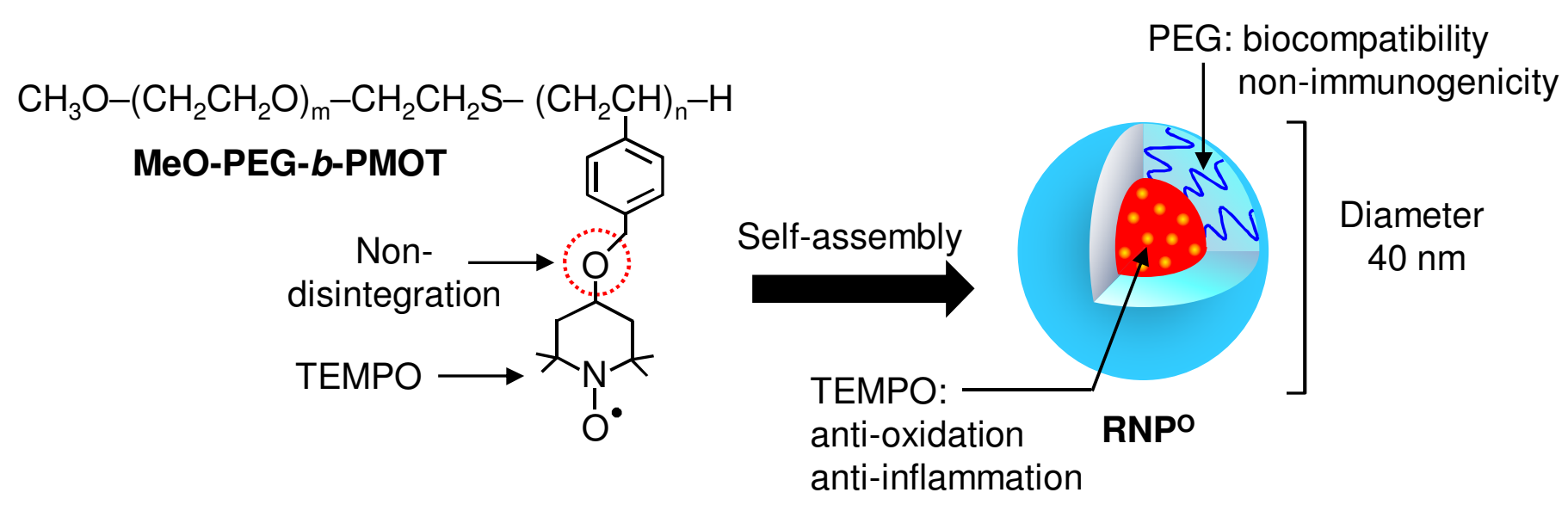

B

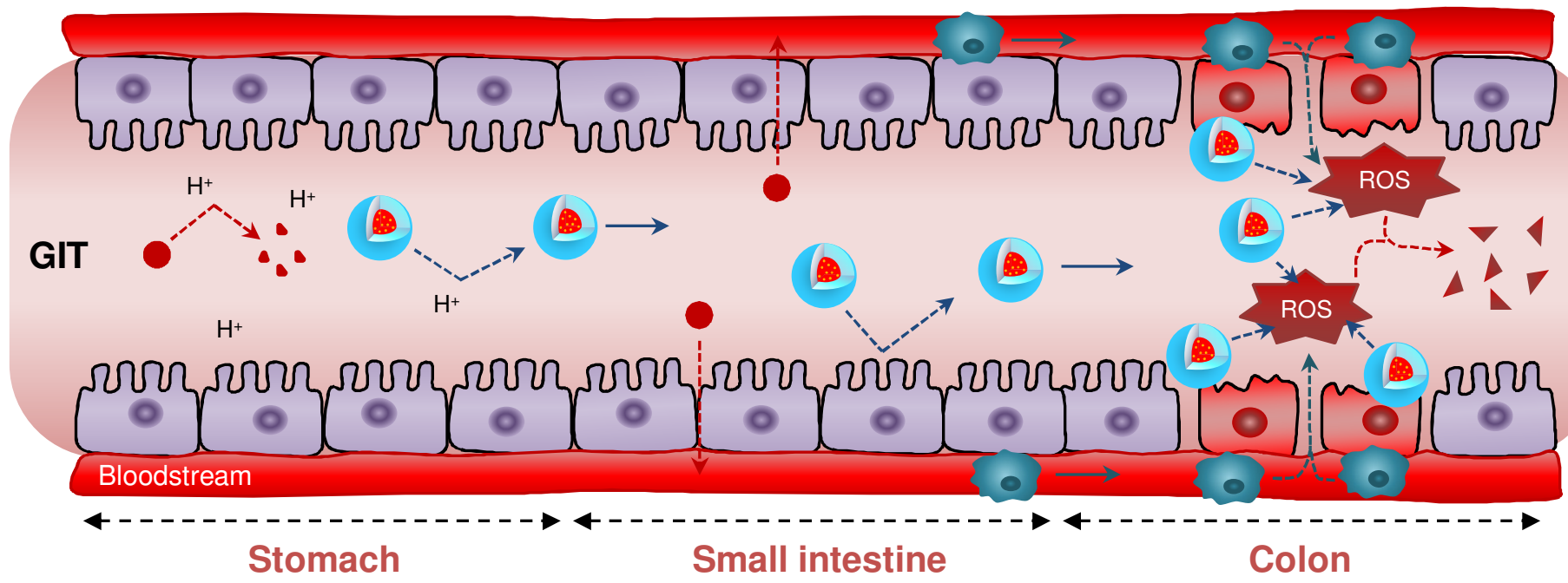

Low-molecular-weight drugs

(2) RNPO

2. Macrophage 


\section{Figure 2}

A

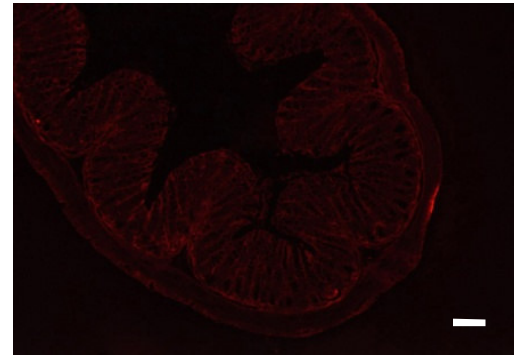

Rhodamine

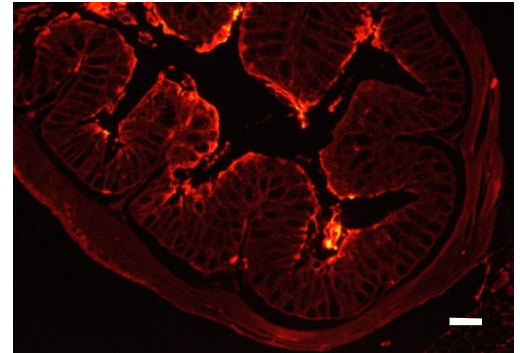

Rhodamine-RNPO

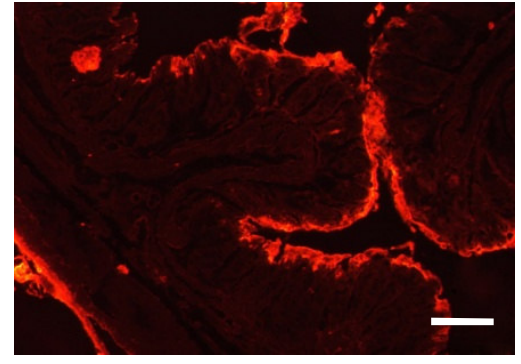

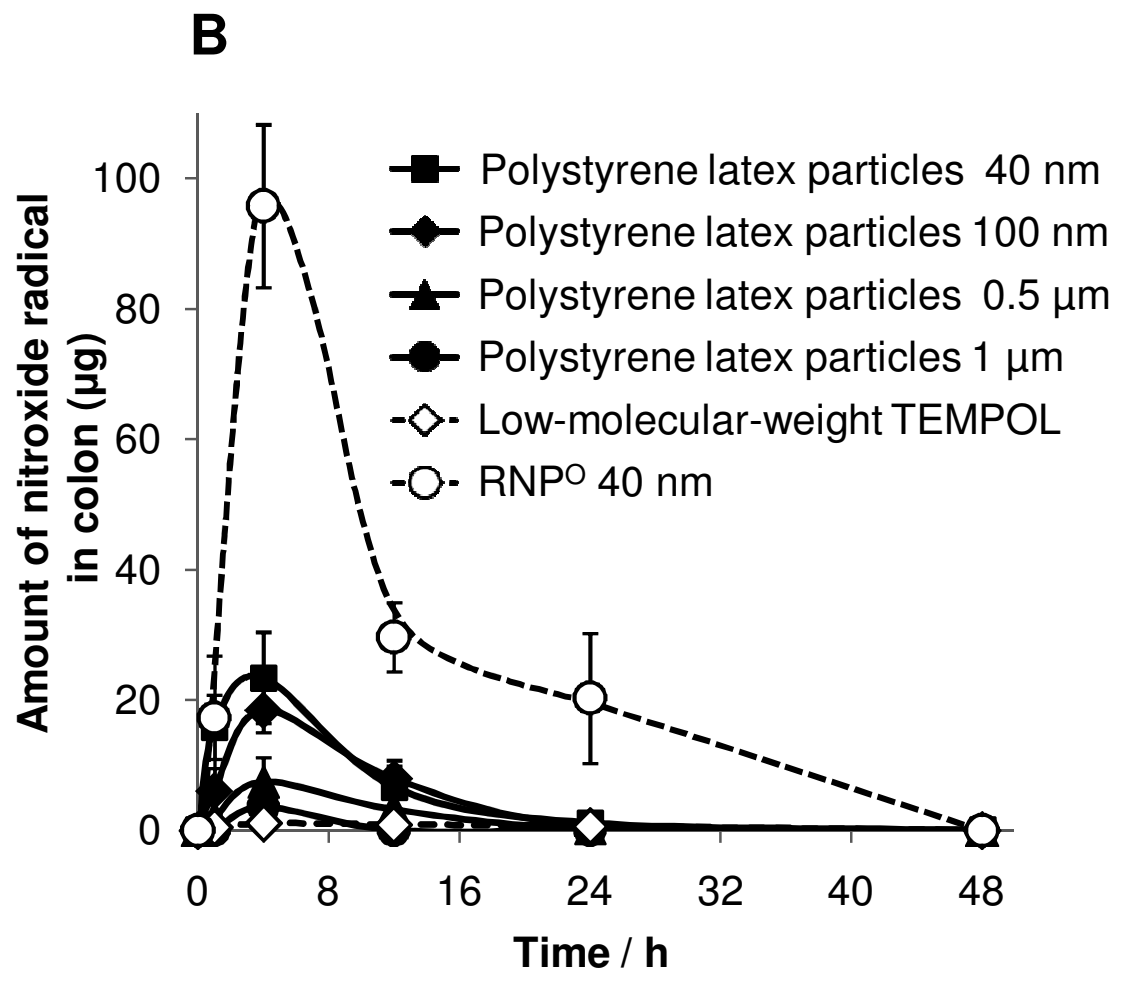

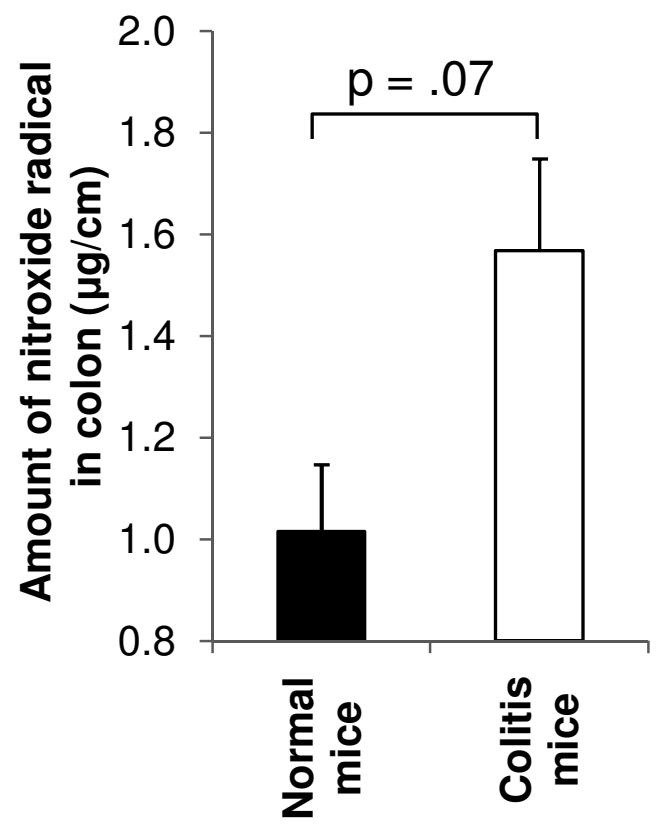


Figure 3

A

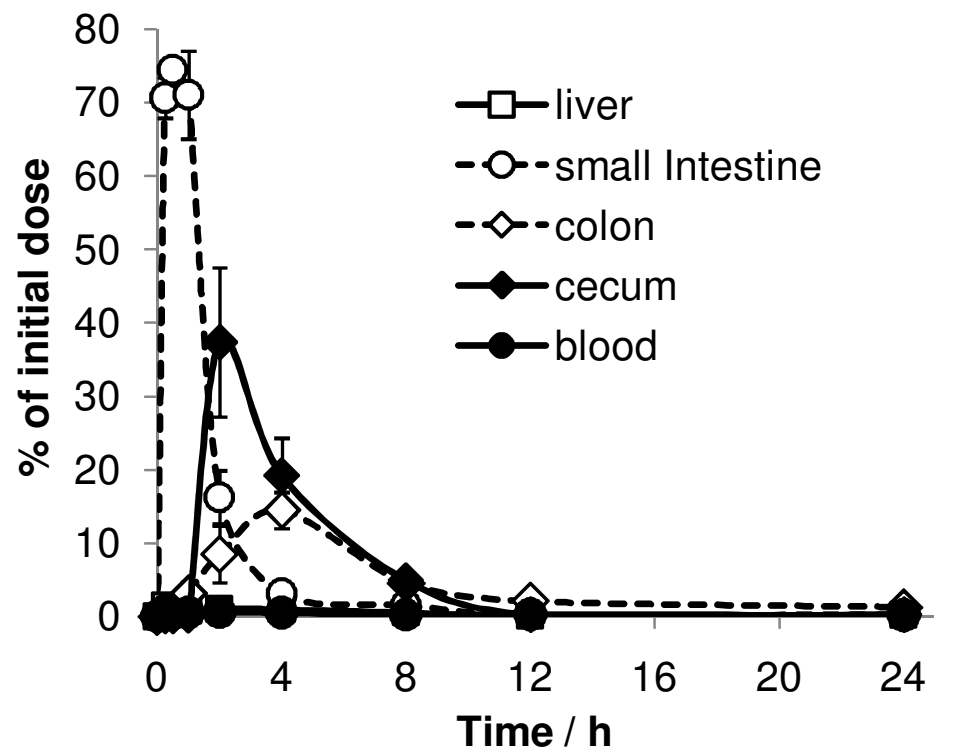

B

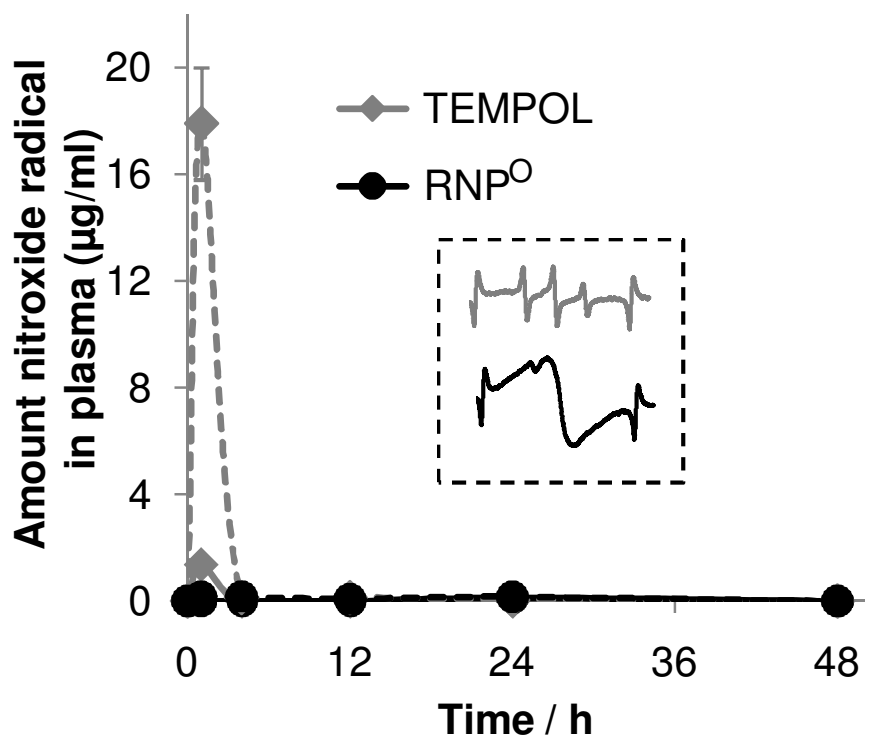


Figure 4

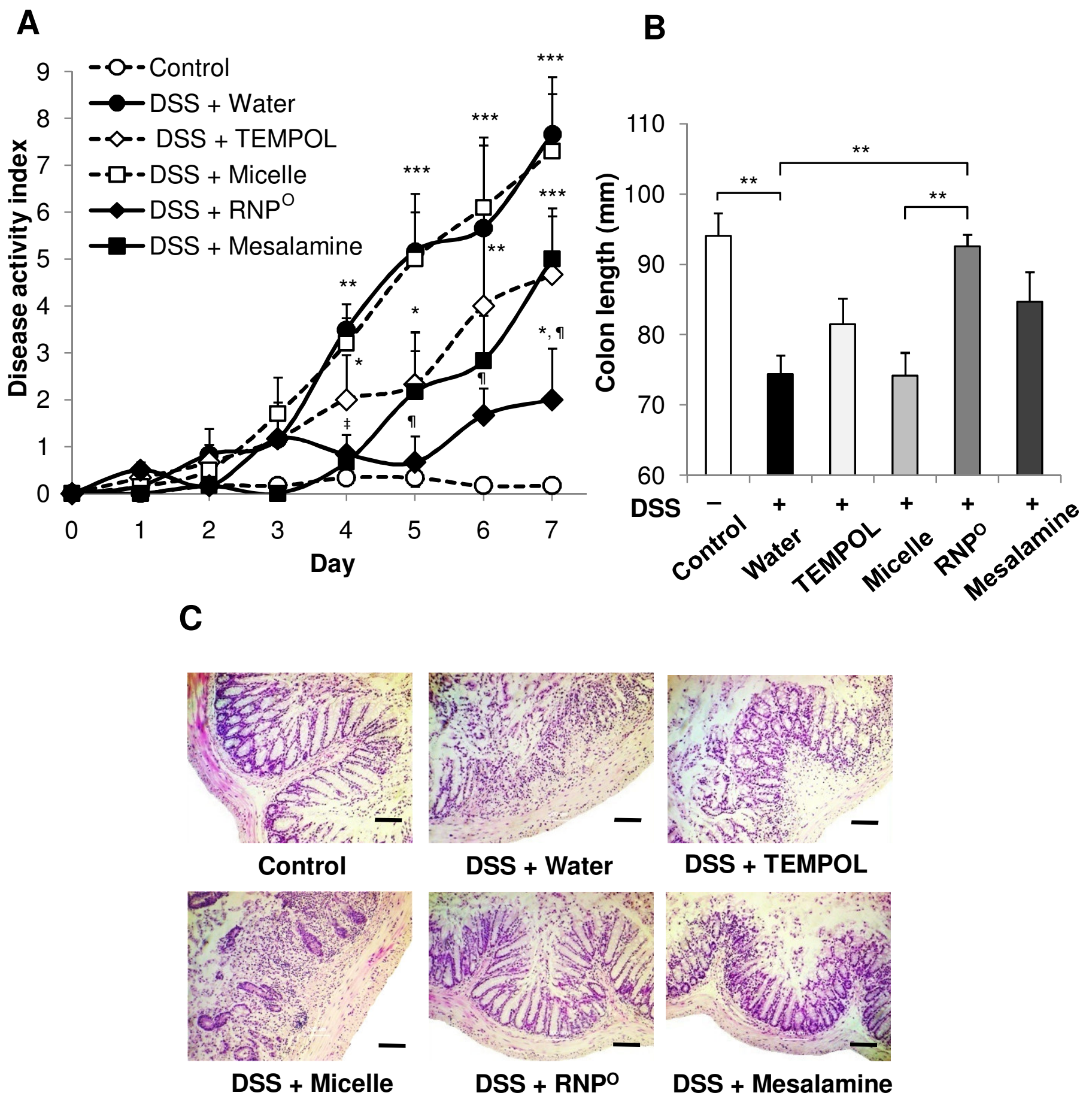


Figure 5

A

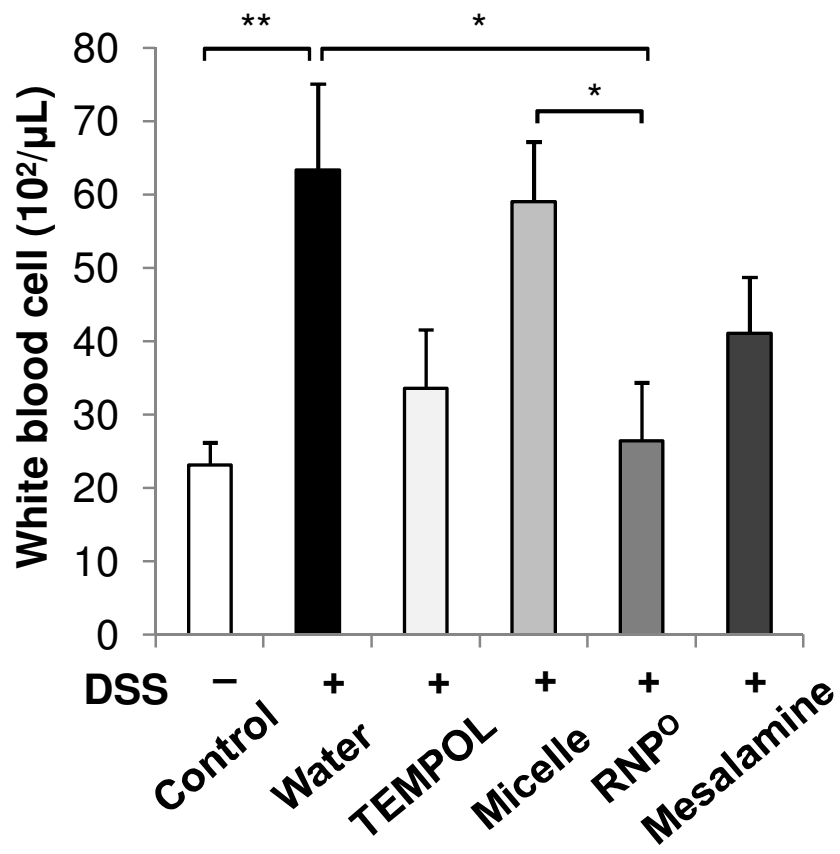

C

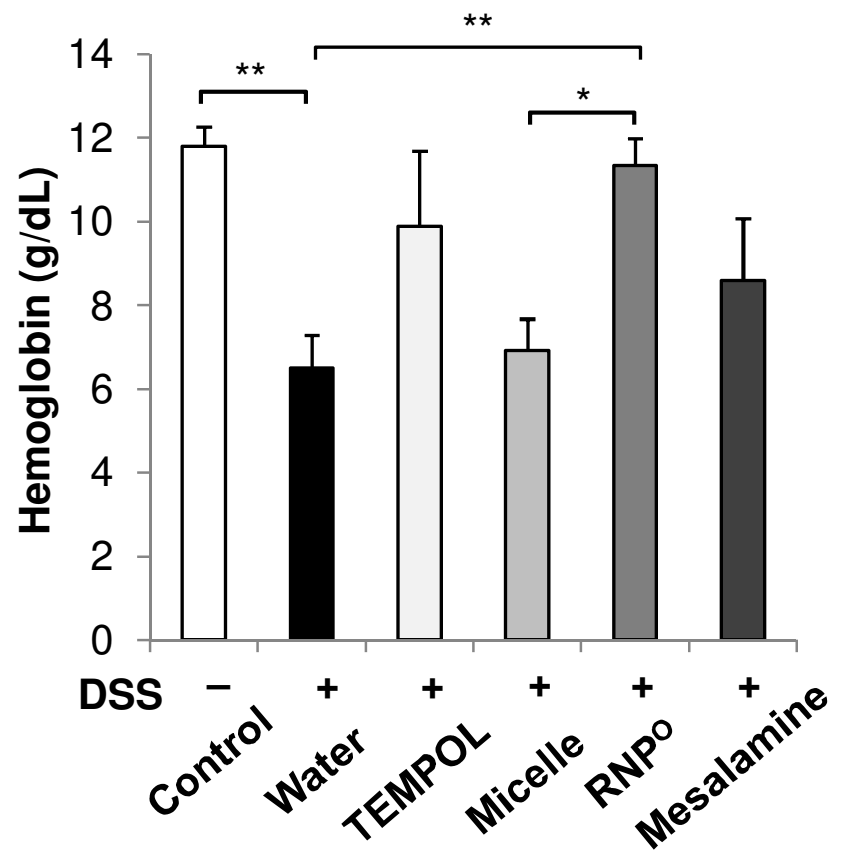

B
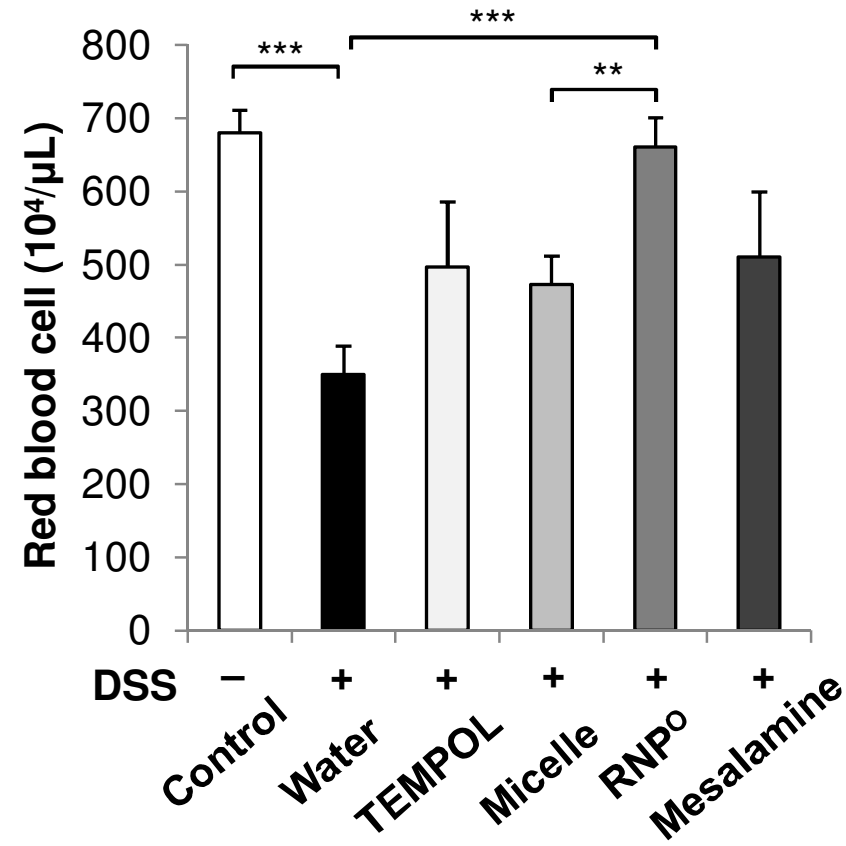

D

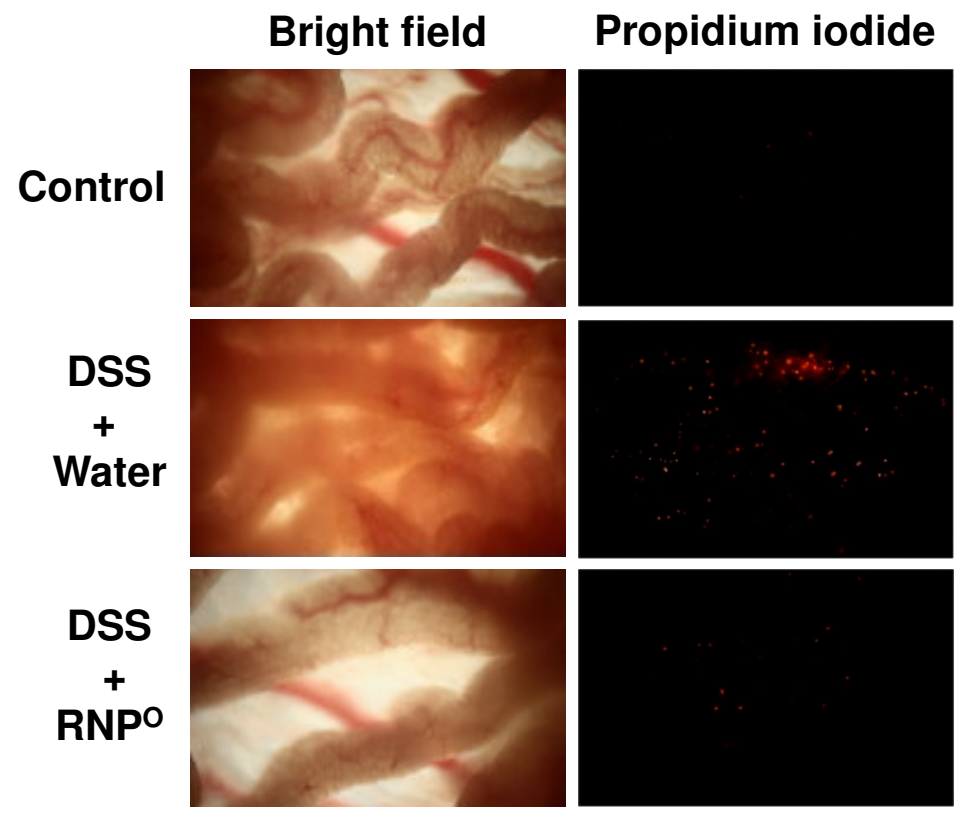


Figure 6
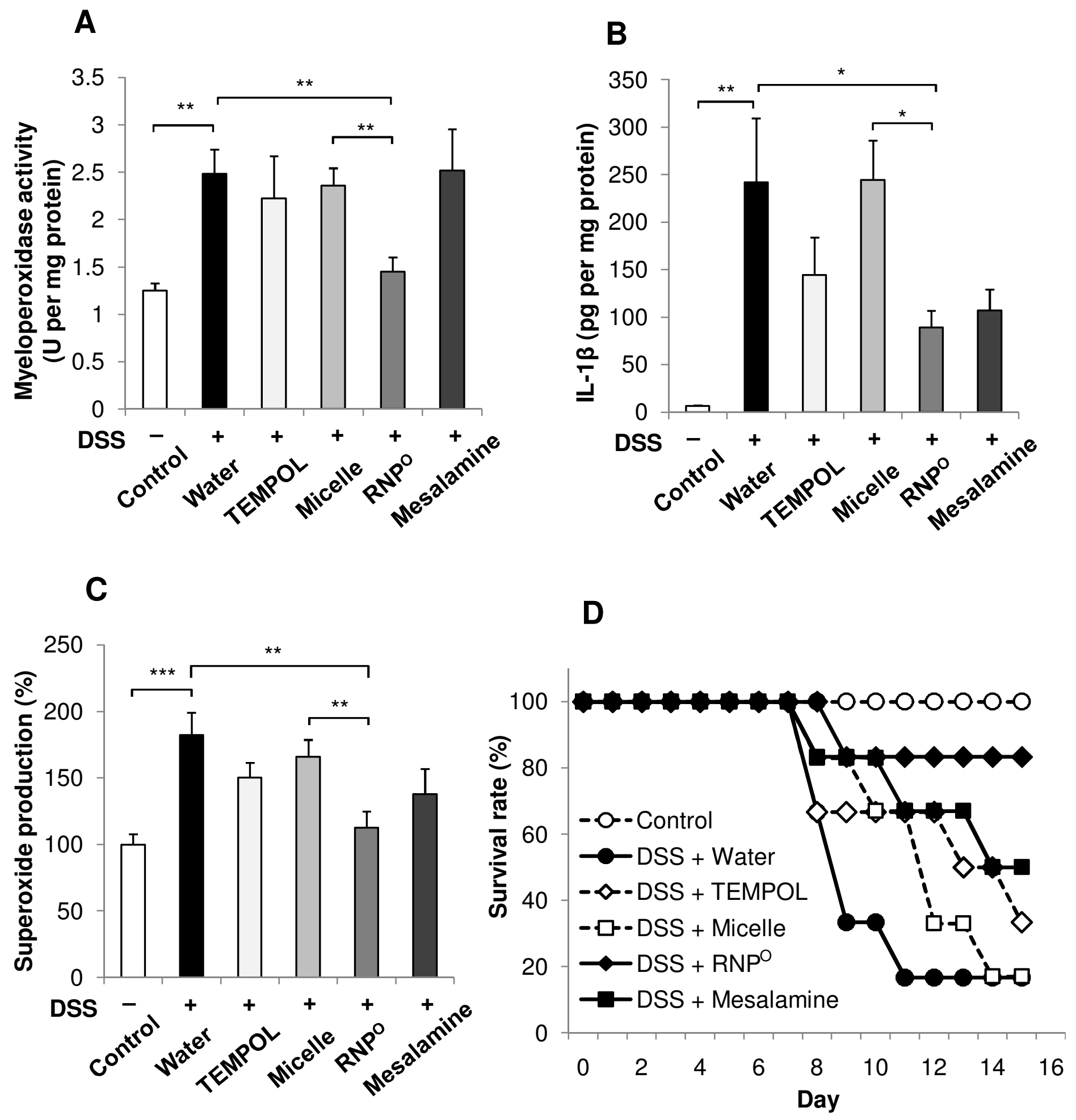